\title{
In-situ and In-operando Cobalt Oxidation Studied by Atom Probe Tomography
}

Sten Lambeets ${ }^{1}$, Mark Wirth ${ }^{1}$, Graham Orren ${ }^{1}$, Norbert Kruse ${ }^{2}$ and Daniel Perea ${ }^{1}$

${ }^{1}$ Pacific Northwest National Laboratory, Richland, Washington, United States, ${ }^{2}$ Washington State University, Pullman, Washington, United States

Heterogeneous catalysis is one of the pillars of the chemical industry and the "green chemistry" concept. However, the sparse understanding of surface mechanisms at molecular scale impedes development of high-performance catalysts and requires development of new tools and methodologies. Cobalt is notably able to dissociate $\mathrm{CO}_{2}$ into $\mathrm{CO}(\mathrm{g})$ and $\mathrm{O}_{2}(\mathrm{~g})$, allowing further conversion to higher value compounds such as long-chain hydrocarbons [1]. Such application leads inevitably to Co surface oxidation. From its pure form $(\mathrm{Co}(0))$ to oxidized ones $\left(\mathrm{CoO}\right.$ and $\left.\mathrm{Co}_{3} \mathrm{O}_{4}\right)$ the formation mechanism remains unclear as well as the surface structure evolution and its influence on the chemical reaction.

In this work, we investigate the $\mathrm{Co}+\mathrm{O}_{2}$ system with Atom Probe Tomography (APT) [2] by two different methods: 1) in-situ using an annex reactor chamber connected on APT; 2) in operando by introducing $\mathrm{O}_{2}(\mathrm{~g})$ directly in the Local Electrode Atom Probe (LEAP) analytic chamber during the ongoing APT analysis. After a cleaning process by field evaporation of adsorbates and native oxide and subsequent atomic surface imaging by Field Ion Microscopy (FIM)[2] of a Co needle in the LEAP, it is then transferred under Ultra High Vacuum into a reactor chamber in which is exposed to pure $\mathrm{O}_{2}(\mathrm{~g})$ at different temperatures and times $\left(\mathrm{P}\left(\mathrm{O}_{2}\right)=10^{-4} \mathrm{mbar}, \mathrm{T}\left({ }^{\circ} \mathrm{C}\right)\right.$ between 200 and $350{ }^{\circ} \mathrm{C}$, $\mathrm{t}(\mathrm{min})$ between 5 and $\left.60 \mathrm{~min}\right)$ . After in-situ oxidation $\left(10^{-4} \operatorname{mbar}\left(\mathrm{O}_{2}\right) ; 300{ }^{\circ} \mathrm{C} ; 10 \mathrm{~min}\right)$, the oxidation process is quenched by transferring back the sample on the cryo-stage in the LEAP analysis chamber, before proceeding with the APT analysis. Oxidation is revealed to be inhomogeneous and strongly influenced by surface crystallographic structure. We detect locally enhanced distributions of $\mathrm{Co}_{2} \mathrm{O}^{\mathrm{n}+}$ and $\mathrm{CoO}^{\mathrm{n}+}$ (Figure 1). $\mathrm{Co}_{2} \mathrm{O}^{\mathrm{n}+}$ is preferentially found deep in the Co volume, surroundings the $\mathrm{CoO}^{\mathrm{n}+}$ enriched zones, drawing the progression of the oxygen in the metal.

In operando mode allows a real time direct observation of the surface oxidation. Surface composition is probed by applying periodic electric pulses, resulting into a virtual "reconstruction" representing a stack of the different surface composition states over time. As depicted on the Figure 2, the oxidation rate progressively increases, starting from pure Co surface (blue), to successively an early and an advanced oxidation stage $\left(\mathrm{Co}_{2} \mathrm{O}\right.$ green and $\mathrm{CoO}$ red) with an increasing $\mathrm{P}\left(\mathrm{O}_{2}\right)$. Inspired by the $1 \mathrm{D}$ Atom Probe principles developed by Kruse et al.[3], the electric potential and the pulse repetition frequencies influence the surface kinetics. It becomes possible to observe the earlier oxidation stages of the surface by varying these parameters. High frequencies, up to $200 \mathrm{kHz}$, delay more the oxidation and allow to observe the earlier stages, while the lower frequencies, down to $25 \mathrm{kHz}$, allows oxidation to proceed. Concretely, we observe a lower oxidation rate of the surface when the pulse frequency is high (higher concentration of $\mathrm{Co}_{2} \mathrm{O}^{\mathrm{n}+}$ ) and a higher oxidation rate (lower concentration of $\mathrm{Co}_{2} \mathrm{O}^{\mathrm{n}+}$ and more $\mathrm{CoO}^{\mathrm{n}+}$ ) when low pulse frequency is used. 
The in-operando mode in APT opens the perspective to study surface kinetics on complex surface structure and chemistry with a high level of details, while the in-situ APT reveals to be a method of choice to follow the path of oxygen under the surface during a chemical process.

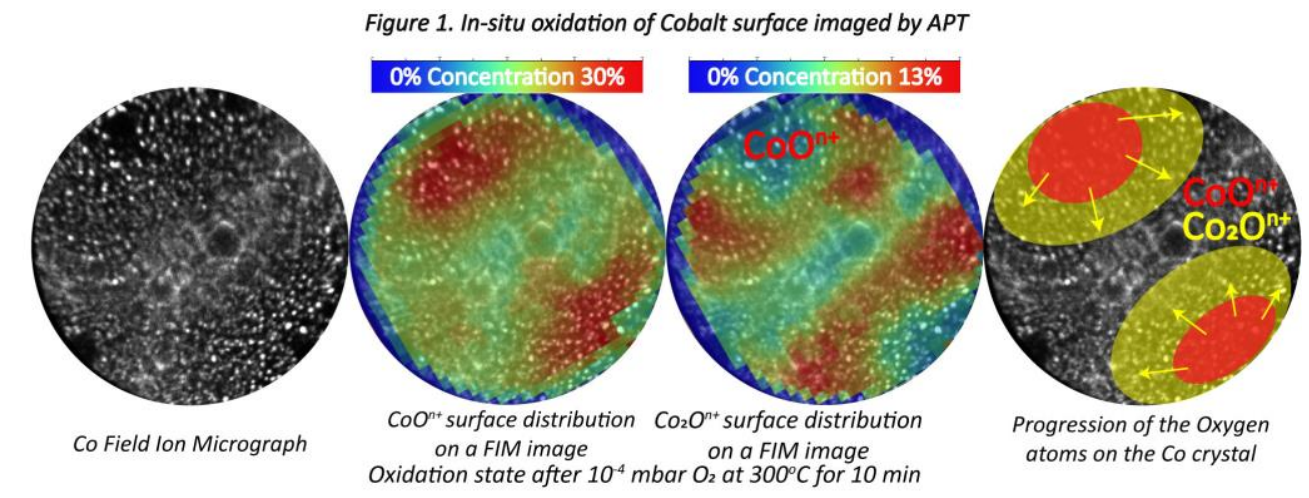

Figure 1. In-situ oxidation of Cobalt surface imaged by APT

Figure 2. In-operando Cobalt surface oxidation imaged by APT

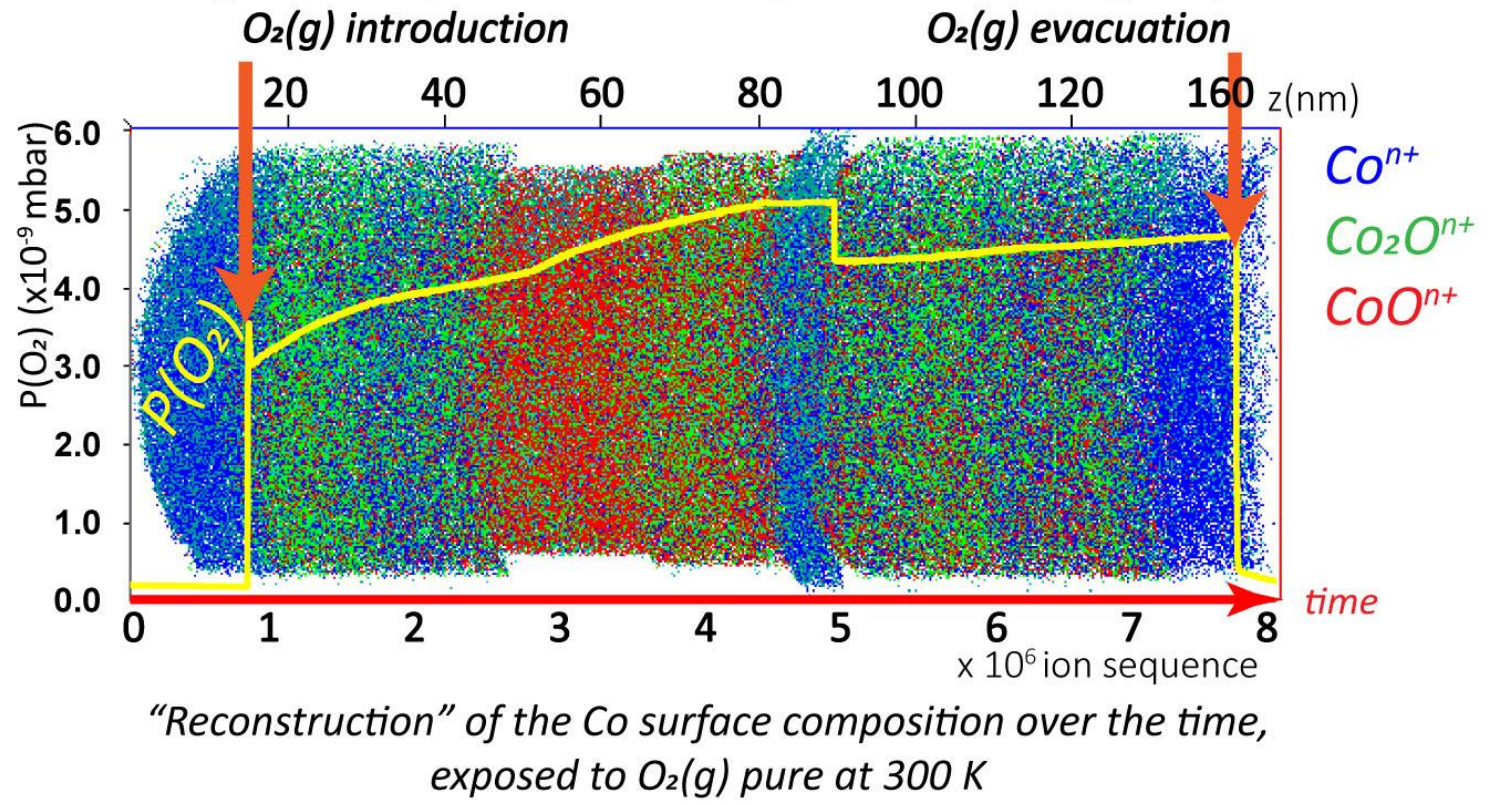

Figure 2. In-operando Cobalt surface oxidation imaged by APT

\section{References}

[1] S. Saedi et al., Renewable and Sustainable Energy reviews 80 (2017) 1292-1311.

[2] B. Gault, M.P. Moody, J.M. Cairnery and S.P. Ringer, Atom probe microscopy, Springer, New York, 2012

[3] Kruse N., Abend G. and Block J.H., Journal of chemical Physics 88 (1987) 1307-1312 